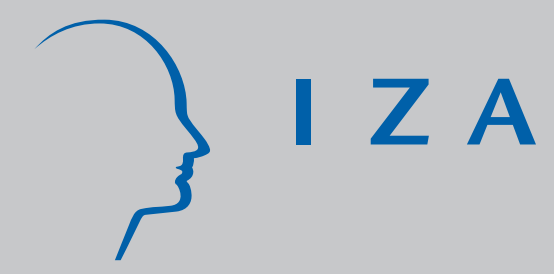

IZA DP No. 1112

\title{
Targeting and Self-Targeting
} in a New Social Assistance Scheme

J ohn Micklewright

Aline Coudouel

Sheila Marnie

April 2004 


\title{
Targeting and Self-Targeting in a New Social Assistance Scheme
}

\author{
John Micklewright \\ University of Southampton \\ and IZA Bonn
}

Aline Coudouel

World Bank

Sheila Marnie

UNICEF Innocenti Research Centre

\author{
Discussion Paper No. 1112 \\ April 2004
}

IZA

P.O. Box 7240

53072 Bonn

Germany

Phone: +49-228-3894-0

Fax: +49-228-3894-180

Email: iza@iza.org

Any opinions expressed here are those of the author(s) and not those of the institute. Research disseminated by IZA may include views on policy, but the institute itself takes no institutional policy positions.

The Institute for the Study of Labor (IZA) in Bonn is a local and virtual international research center and a place of communication between science, politics and business. IZA is an independent nonprofit company supported by Deutsche Post World Net. The center is associated with the University of Bonn and offers a stimulating research environment through its research networks, research support, and visitors and doctoral programs. IZA engages in (i) original and internationally competitive research in all fields of labor economics, (ii) development of policy concepts, and (iii) dissemination of research results and concepts to the interested public.

IZA Discussion Papers often represent preliminary work and are circulated to encourage discussion. Citation of such a paper should account for its provisional character. A revised version may be available on the IZA website (www.iza.org) or directly from the author. 


\section{ABSTRACT \\ Targeting and Self-Targeting in a New Social Assistance Scheme*}

The analysis of targeting of cash benefits is typically silent on whether any success is due to encouraging claims from the poor or to the decisions of administrators on the claims they receive. By contrast, the paper models the probabilities of households' knowledge of a new social assistance scheme, of a claim conditional on knowledge, and of an award conditional on knowledge and claim. It uses household survey data from Uzbekistan where a new social assistance benefit is administered by community organisations. The paper therefore also illustrates problems of design of decentralised social assistance schemes in developing countries.

JEL Classification: $\quad$ I38, H53, O15, P35

Keywords: $\quad$ targeting, self-targeting, social assistance, Uzbekistan

Corresponding author:

John Micklewright

Division of Social Statistics

School of Social Sciences

University of Southampton

Highfield

Southampton SO17 1BJ

United Kingdom

Tel.: +442380592167

Fax: +442380593846

Email: jm4@soton.ac.uk

\footnotetext{
* This research was funded by the European Union TACIS-ACE scheme, the Save the Children (UK) Erica Wheeler memorial fund, and the World Bank 'Women in Development' fund. It also received support from the World Bank Special Program Grant to the MONEE project at UNICEF IRC. We are grateful to Alisher Ilkhamov and his colleagues in EXPERT Centre, Tashkent, for collecting the household survey data used in the paper, and for comments to Harold Alderman, Stephen Jenkins, Jeni Klugman and participants at seminars at Essex, Florence, Southampton, Syracuse and Washington.
} 


\section{Introduction.}

The typical analysis of the targeting of 'last-resort' cash benefits on needy households by local benefit administrators is silent on whether any success is due to encouraging claims from the poor and discouraging them from the rich or to the decisions of administrators on the claims they receive, given the funds at their disposal. By contrast we model the probabilities of a household's (i) knowledge of a new social assistance scheme, of (ii) a claim conditional on knowledge, and (iii) of an award conditional on knowledge and claim. To do this we exploit information that is rarely collected in household survey data on each stage in the process of receiving benefit. Although there has been much interest in self-targeting in the benefit literature, the empirical analysis of take-up and targeting has very seldom been able to distinguish among the different types of non-recipient households - those who are ignorant of the benefit scheme, those who decide not to make a claim, and those who claim but are denied benefit. ${ }^{1}$ Our first contribution is to use data that distinguish these different categories of non-receipt to show how a richer picture can be obtained of the targeting process.

Our second contribution is to analyse problems of benefit design in countries in transition from the planned economy. The data we use come from Uzbekistan, the largest of the former Soviet Central Asian republics. Some of the problems are common to those elsewhere and have been analysed in the existing literature (e.g. Besley and Kanbur 1993, Grosh 1994, Atkinson 1995, and Galasso and Ravallion 2002). But the particular nature of transition gives them heightened importance and throws up new challenges for targeting. First, agents to administer new schemes must be chosen - administration of state benefits cannot be a function of state-owned enterprises, as was often the case in the past. Second, the reaction of the populace, unused to targeted social assistance in countries where poverty was unrecognised, is unknown. Will knowledge of a new scheme spread quickly? And will households recognise the rules of the scheme in deciding whether to apply, implying an important element of self-targeting? Third, suitable indicators of need must be defined. Cash income from employment and state transfers was the basis for eligibility for an allowance paid to large families in the former USSR and it plays a central role in assistance schemes in OECD countries. But this is too restrictive an indicator of household welfare in many transition economies, especially those at lower levels of development.

The social assistance scheme from Uzbekistan that we analyse is administered by traditional

\footnotetext{
${ }^{1}$ Much of the interest in self-targeting has been in the context of schemes in developing countries with a work requirement, something missing from both the Uzbek scheme analysed in this paper and many social assistance benefits in industrialised countries.
} 
pre-Soviet local community groups, the "Mahallas", and has attracted attention as a possible model for replication elsewhere. About 1 in 5 households received benefit in 1995, the first year of operation. Details of the scheme's design suggest that exclusion of the needy and inclusion of households not in need could be common. The Mahallas have enormous discretion and there is no national set of necessary or sufficient conditions for benefit. Our analysis of the Mahalla scheme sheds further light on whether local community groups can act as effective agents of targeting for national government, a prominent question in recent literature on targeting (e.g. Alderman 2002).

Section 2 lays out a simple empirical framework for assessment of targeting success, applicable in any country to any cash benefit. This relates probabilities of knowledge, claim and award to indicators of household welfare and of horizontal inequities. We discuss how this relates to models of 'take-up' in the targeting literature. Section 3 gives the essentials of the Mahalla benefit scheme, describes the household survey data that we use to analyse it, and provides an initial picture of households' knowledge, their claims and the benefit awards. Section 4 presents results of logit models for the probabilities of knowledge, claims and awards separately, highlighting the role of self-targeting through claims. Section 5 concludes.

\section{A framework for assessing targeting}

Cash benefits do not fall on households like manna from heaven. In general, three events need to take place before a benefit is received. First, households need to be aware of its existence. Second, they then must make a claim. And third, a benefit agency has to take a decision on whether or not to make an award. Hence the probability of being in receipt of benefit may be written as:

$$
\operatorname{Pr}(\text { receipt })=\operatorname{Pr}(\text { award } \mid \text { claim and knowledge }) . \operatorname{Pr}(\text { claim } \mid \text { knowledge }) . \operatorname{Pr}(\text { knowledge })
$$

In principle, equation (1) applies to any type of benefit in countries at any level of development. In practice, however, it may be possible to assume that one or more of the probabilities on the right hand side are equal to either one or zero for all intents and purposes. For example, there may be complete knowledge of a well-established universal family allowance such as exists in several European countries. (This could be true even among those with no children, meaning that there is no temporary problem of knowledge acquisition on the birth of a child.) The probabilities of claims by households with children and of award following claim should also be very high for such benefit schemes - and very low for households without children. The partitioning of the population into groups with claim (and award) probabilities equal to one and zero means that 'self-targeting' plays a big part in the benefit assignment process. One result is that the benefit agency is not swamped 
with frivolous applications, resulting in high administration costs.

With other types of benefit, where eligibility conditions are less straightforward, an assumption that the probabilities in (1) polarise to zero or one becomes untenable. Many means-tested benefits have complex rules governing eligibility. Even knowledge of their existence will be less than complete. Claim and award probabilities will take on values well within the unit range for both eligible and ineligible households. Psychic (e.g. stigma) and other costs of claiming (e.g. the money and time needed to travel from a remote district to queue-up in an urban centre) may result in applications not being made by some households eligible under the rules. Administration errors both intentional and accidental - may deny eligible households of an award or may favour the ineligible. Knowing the possibility of error by the benefit agency, fraudulent claims may be made by non-eligible households. Or awards may not be made since a local benefit agency has simply run out of money and is not obliged to make payments by national rules.

Where a scheme has been newly introduced, diffusion of knowledge of its existence cannot be expected to be instant even if the rules are quite straightforward. And where the rules governing eligibility are far from clear-cut, the probabilities of claim conditional on knowledge and of award conditional on claim will be subject to further variation. Both situations characterise the Uzbek Mahalla social assistance scheme considered in this paper. Our data are from a household survey conducted only nine months after the scheme was introduced. The Mahallas are an institution of the majority ethnic group and not of the ethnic minorities, e.g. Slavs. There are national guidelines for the Mahallas' decision-making process, included a list of indicators of need, but the final decision rests with the Mahallas with no right of appeal to a higher authority. The Mahallas have a block grant from central authorities for financing benefits that appears to take no account of the degree of local need and they have no obligation to give money when they have exhausted these funds.

The ability to model the different parts of equation (1) depends on the nature of the available data. In many household survey data sets there is information on receipt of state benefits, but nothing on the reasons for non-receipt. In this case only the overall probability of receipt can be modelled. ${ }^{2}$ Nevertheless, if the rules for eligibility are very clear so that a good estimate of entitlement for a household may be made (e.g. income less than a given threshold and household head not working), one may model the following:

$\operatorname{Pr}($ receipt | eligibility).

${ }^{2}$ Data drawn from administrative records of the benefit agency could obviously allow the probability of an award conditional on claim to be analysed. However, they would tell nothing 
This is then interpreted as a behavioural equation of 'take-up' of entitlement (e.g. Blundell et al 1988). Knowledge is assumed complete and there is no allowance for administration errors by the benefit agency, i.e. both $\operatorname{Pr}($ knowledge $)=1$ for all households and $\operatorname{Pr}($ award $\mid$ eligibility $)=1$ for all claimants. The approach also assumes no errors in the researcher's calculations of entitlement, implying that the survey's definition of income corresponds exactly to the benefit agency's and that it is measured perfectly. In this situation, equation (2) gives $\operatorname{Pr}$ (claim | eligibility). However, this is not the same as $\operatorname{Pr}$ (claim | knowledge), one of the probabilities of interest on the right hand side of equation (1). We need to allow for the possibility that the ineligible may apply, something that is not observed in a typical household data set. ${ }^{3}$

One way to think of incomplete take-up is that it results in Type I targeting error - exclusion from coverage of needy households. Type I error may result as well from administration errors, but these may also lead to inclusion into coverage of household that are not in need - Type II error. Viewed in this way both forms of error reduce a scheme's horizontal and vertical efficiency in targeting (Weisbrod 1970). However, as Atkinson (1995) point outs, assessment along these lines depends on whether the objectives of policy are clear and on how much agreement there is about those objectives (see also Besley and Kanbur 1993). This is not the case in the Mahalla scheme analysed in this paper, which has no necessary and sufficient conditions for benefit that reflect policy on what constitutes a needy household. (Nor at the time our data were collected was there any official poverty line that might serve as a yardstick.)

In this situation an alternative approach can be taken that does not depend on a prior clear-cut definition of what constitutes a household that should have benefit and one that should not. We proceed as follows. Exploiting the information available to us on the different stages of benefit receipt, each of the three events on the right-hand side of equation (1) can be related to two sets of observed characteristics of households:

$$
\operatorname{Pr}(\text { event })=\mathrm{F}(\boldsymbol{\beta} \mathbf{X}, \boldsymbol{\delta Z})
$$

about probabilities of knowledge or of claim conditional on knowledge and in addition such data are not often available to the researcher.

${ }^{3}$ Motivated by the errors both in benefit administration and in the researcher's measurement of entitlement, Duclos (1995) makes progress with data where only receipt is observed by making some assumptions about the form of these errors. However, the assumptions are very strong ones and Pudney (2003) argues that they are unrealistic. His conclusions on the impact of measurement error on binary choice models of take-up are sobering: 'quite modest degrees of error may generate biases sufficient to distort completely a policy analysis based on them' (Pudney 2001). 
where $\mathbf{X}$ is a vector of household welfare characteristics chosen by the researcher and $\mathbf{Z}$ is a vector of characteristics intended to pick up horizontal inequity e.g. household location and race. A welltargeted scheme - viewing the scheme as a welfare analyst rather than as a government official requires $\boldsymbol{\beta} \neq 0$, with coefficients of the right sign and a magnitude sufficient to produce a reasonable range of predicted probabilities. It also requires $\boldsymbol{\delta}=0$. The estimation of equation (3) for each of the three probabilities on the right hand side of equation (1) shows where targeting is actually achieved. In principle this approach could be applied to any cash benefit, provided that information on knowledge, claim and award is available. Even in countries where the definition of eligibility for a benefit is firmly laid-down by central government there may be genuine debate as to its suitability, implying that the welfare analyst may not wish to restrict the definition of need to the official one.

Finally, it should be noted that our estimation strategy is essentially designed to show which household characteristics are important at each stage of the targeting process. It is not a modelling approach that is intended to uncover directly the behaviour of all the agents involved. This distinction is particularly obvious in our treatment of the equation for $\operatorname{Pr}$ (award $\mid$ claim and knowledge) since we do not observe any characteristics of the Mahallas themselves that could be brought to bear to model Mahalla behaviour.

\section{The benefit scheme and the survey data}

\section{a) The Mahalla social assistance scheme}

The social assistance benefit administered by the Mahallas was started in Autumn 1994, coinciding with the removal of food subsidies, and was the first attempt in Uzbekistan to provide targeted assistance of last resort. Administrative data record that about a fifth of all households received benefit in 1995. The level of support is modest. Among households receiving assistance in the survey used in this paper, benefit averaged only a quarter of total cash income received or due from the previous month. The details of the scheme given below relate to how it operated in our survey year, $1995 .^{4}$

The Mahallas are neighbourhood groups based around a group of elders that have existed for centuries in the Uzbek and Tajik cultures. Since the collapse of the communist party apparatus, they have offered the central authorities an alternative instrument of social control. The chairman

\footnotetext{
${ }^{4}$ More information is given in Coudouel et al (1998).
} 
and secretary of each Mahalla are paid a salary by the local authorities and candidates for chairman (who in principle are elected) have to be approved by local government offices. There are about 12,000 Mahallas in Uzbekistan, each covering an average of only about 400 households.

The Ministry of Labour issues instructions to the Mahallas on how to identify needy households. The criteria that should be taken into account include household size and composition, activity status of household members, income, consumer durables, land and other assets. But the instructions underline that there are no necessary or sufficient conditions and that Mahallas have the right to "independently determine principles and criteria" for awards.

On the one hand, the highly decentralised and flexible nature of the scheme exploits local knowledge of household circumstances. This reduces the problem of asymmetric information between benefit administrators and potential clients and weakens households' incentive to conceal their true circumstances. The scheme takes into account a variety of aspects of living standards rather than restricting the measurement of welfare to a single scalar in the form, say, of cash income. In principle, the discretion given to the Mahallas allows community preferences to be reflected in the scheme's administration. And by using what is formally a non-governmental organisation, the scheme lowers administrative costs for the state budget.

On the other hand, the discretion given to Mahallas means that subjectivity and arbitrariness of a negative kind can creep in. The award process is fairly public which may reduce the propensity to claim. Slavic and other households not of Central Asian ethnicity, which form an important minority in large urban areas of Uzbekistan, may have a much less positive attitude to the Mahallas than ethnic Central Asian households. And there could be discrimination against ethnic or religious minorities in the administration of claims, either reflecting genuine majority preferences within the local community that the central authority would like to suppress, or resulting from abuse of power by Mahalla officials. Administrative skills in applying the guidelines can be expected to vary widely given the very small average size of each Mahalla. The lack of any appeal mechanism against decisions on claims aggravates all these problems. Finally, the system of allocating central funds to each Mahalla apparently takes little or no account of their average living standards and hence likely variation in the demand for benefit. In short, there are many reasons for being concerned about horizontal equity.

\section{b) The household survey data}

The source we use is the European University Institute and University of Essex Survey in Uzbekistan (EESU), which interviewed 1,581 households in three of Uzbekistan's 14 regions in 
June 1995, nine months after the Mahalla social assistance scheme had been introduced. These regions - Tashkent city (the capital), Fergana and Karakalpakstan - represent different levels of average living standards (Coudouel et al. 1997). Most indicators show living standards in Tashkent city (which contains over 2 million people) to be higher than elsewhere. Fergana, an agricultural region with some large urban areas, comes in the middle of the spectrum, while Karakalpakstan is Uzbekistan's poorest region, bordering the Aral Sea and suffering from major environmental problems associated with the sea's retreat. (Karakalpakstan is the region with the highest infant mortality rate and the lowest per capita income.) The sample consists of about 500 households in each region, designed to be representative at the regional level. ${ }^{5}$

The survey instrument contained a block of questions on the Mahalla social assistance scheme, addressed to the head of the household. The rest of the household questionnaire contained sections on household composition, housing amenities and ownership of durable goods, access to and use of private agricultural plots, and private transfers. A questionnaire to all adults aged over 16 collected information on education, employment and incomes. Finally, basic anthropometric measures (height and weight) were collected from all pre-school children, and are only very weakly correlated with household income, providing valuable additional information on welfare (Micklewright and Ismail 2001). The survey therefore provides a range of welfare indicators that may be used to assess targeting of public policy. Unfortunately, however, we were unable to supplement the survey data with any information on the Mahallas in which the respondent households reside. For example, we do not observe the funds allocated to these Mahallas for social assistance expenditure and hence we cannot investigate how this aspect of the system helps or hinders targeting.

\section{c) a first look at targeting}

Overall, nearly 1 in 5 households were receiving benefit at the time of the survey (or had previously done so). Table 1 shows how receipt varies with cash income received in the month prior to the survey (income excludes any support from the Mahalla). Column 1 shows that the percentage of households with benefit falls from over a quarter in the bottom two quintiles groups of cash income to 10 percent in the highest, with the big drop coming in the middle of the distribution.

How does this come about? Column 2 shows that knowledge of the scheme is high and falls

\footnotetext{
${ }^{5}$ Our descriptive results employ weights designed to produce a sample representative of the total population of the three surveyed regions. We thus weight by region and also correct for some under-sampling in rural areas (for details see Coudouel 1998).
} 
with income - twice as many households in the top two quintile groups do not know about the scheme as in the bottom two. This indicates an element of self-targeting - those with less need are less like to inform themselves, although it is of concern that 1 in 7 households in the bottom fifth are ignorant of the scheme. Only half those knowing about the scheme and in the bottom fifth had applied (column 3). But claims for benefit among those with knowledge do fall sharply with income; more than twice as many households in the bottom two quintile groups had applied for support than in the top two. Turning to the final stage, awards, it is striking that conditional on a claim being made, a rich household is broadly speaking as likely to get benefit as a poor household (column 4). It is the poorer households' better knowledge and, especially, greater propensity to apply that leads to their higher probability of receipt.

Column 5 provides information on the other part of the assessment procedure - the amount of benefit awarded. Average benefit paid to recipients hardly changes across income groups. Benefit awards certainly do vary across households (the coefficient of variation is 0.6) but not, apparently, with income. This means that the shares of total benefit going to each income quintile, shown in column 6 , are driven by the variation in the frequency of receipt (column 1). Further analysis revealed little association of benefit amounts with any observed household characteristics, a finding of some concern. In what follows we therefore focus on explaining the probability of receiving a benefit payment irrespective of the amount. Here household characteristics do indeed appear to matter.

Cash income over one month (the only period for which the EESU collected income data) is a far from ideal measure of household welfare for a country at the level and stage of development of Uzbekistan. There is a large agricultural sector, which is an important source of income in kind for many households including those not engaged in agriculture as a primary activity. ${ }^{6}$ Assessment and verification of formal income is made harder in a transition economy than a planned economy due to growing self-employment and the loosening of formal controls and monitoring of economic activity. All this helps explain why the association of cash income with receipt is not that strongthe poorest 40 percent of households receive only 60 percent of total benefits paid. A fuller investigation of targeting requires analysis of a number of different welfare indicators and to do this we turn to multivariate analysis using the framework described in Section 2.

\section{Knowledge, claim and award}

\footnotetext{
${ }^{6}$ The same is true of many other countries in the region, as widely documented in new household surveys (e.g. see World Bank 2000: 154).
} 
Our framework requires us to distinguish between characteristics that measure household welfare, $\mathbf{X}$, and those intended to test for horizontal equity, $\mathbf{Z}$.

On one argument, household consumption or income of all types (the distinction between the two is not of course trivial) is the appropriate measure of welfare. Welfare is not considered a multi-dimensional vector and the problem is merely that we do not observe the ideal scalar. Characteristics of the household other than monthly cash income are of interest only because they proxy this unobserved ideal. The alternative argument is that living standards do indeed depend on more than consumption alone. The insecurity of unemployment may generate disutility other than through reduced current consumption. Low nutritional status (of which food intake is only one determining factor) increases the risk of ill-health or even death, and reduces physical and mental capabilities. A cash transfer may not be the appropriate policy response to low welfare in dimensions such as these (as opposed to direct intervention in the labour market or in systems of public health). But that issue is separate from the simple question we want to answer here of whether it is in fact the low welfare households that are most likely to receive social assistance.

The variables we select for vector $\mathbf{X}$ are intended both to proxy unobserved income (or consumption) - or its lack - and to directly measure welfare in their own right. (Some are explicitly mentioned in the guidance given to Mahallas, e.g. numbers of children and of unemployed adults.) Besides monthly cash income (defined as in Table 1), the variables in $\mathbf{X}$ are an index of durable goods ownership, whether the household owns its own means of motorised transport (car or motorbike), whether it owns land (or has a "dacha plot"), whether it owns livestock (cattle, sheep or goats), whether the household is headed by a woman, whether there is an unemployed adult in the household, the number of children in the household, and the long-term anthropometric status of young children (height for age). ${ }^{7}$ In principle, several of these could be endogenous to benefit receipt (via behavioural responses through work effort and via increased consumption expenditure) but benefit amounts are very modest and we believe that this is not a problem in practice.

\footnotetext{
${ }^{7}$ Height for age reflects factors such as food intake and health status. Some 15 percent of children 0-6 in the sample are moderately or severely 'stunted' (height-for-age more than two standard deviations below the reference) and we enter a dummy in the models that takes the value one if there is at least one stunted child in the household. Stunting occurs slowly, building up through childhood, and is very unlikely to be endogenous to benefit receipt given that the Mahalla scheme had been in existence for only 9 months at the time of the survey. However, we eschew information in the survey on weight-for-height, a short-term measure of nutritional status, on grounds of potential endogeneity.
} 
Horizontal equity requires those in similar circumstances be treated in similar ways. Conditional on adequate measures of household welfare, a just scheme should result in no variation of receipt with "non-welfare" measures. We test for such variation by entering in the $\mathbf{Z}$ vector several crude measures of residence together with a variable measuring ethnicity: we include dummy variables for Karakalpakstan and Fergana, for towns (urban areas below 100,000 people) and for rural areas, and for households headed by someone of Central Asian ethnicity. The allocation of funds to Mahallas may favour different parts of the country. Even funds distributed uniformly (as appears to be the case) should mean it is easier for a poor household to get benefit in some areas than in others. The operation of the scheme may be more generous in the countryside where monitoring may be harder. The nature of the Mahallas may favour majority Central Asian ethnic groups as discussed earlier. (Central Asian ethnicity is almost universal in Karakalpakstan but nearly 1 in 10 households in Fergana and a half in Tashkent are of another ethnic group, typically Slav.)

Of course, these indicators in $\mathbf{Z}$ may partly proxy measures of welfare that should be in $\mathbf{X}$ but which are unobserved to us. Some of these may be observable to the Mahallas investigating claims. One of the purposes of decentralised social assistance is that local agents should take locally-available information into account, information that may be hard to collect in a household survey as well as hard to measure by central authorities (see also Alderman 2002). For example, there may be greater need in rural areas that is unmeasured in our data. Karakalpakstan, as we have noted, is the most deprived region in Uzbekistan, and our welfare indicators are unlikely to pick up all aspects of that deprivation. However, it is also unlikely that all of the association found between receipt and the variables testing for horizontal equity can be explained by their correlation with measures of household welfare that are unobserved in the survey data.

\section{b) results}

Table 2 presents results of logistic regressions of each of the three probabilities on the right hand side of equation (1): knowledge, claim conditional on knowledge, and award conditional on knowledge and claim. The logistic form implies the probability in each case, $\mathrm{P}$, for an individual $\mathrm{i}$ is given by the function $1 /\left[1+\exp \left(-\left[\boldsymbol{\beta} \mathbf{X}_{\mathrm{i}}+\boldsymbol{\delta} \mathbf{Z}_{\mathrm{i}}\right)\right] .{ }^{8}\right.$ In the case of the claim and award equations, the results are obtained conditional on membership of the population represented by the sub-sample

\footnotetext{
${ }^{8}$ The marginal impact of a welfare variable $X_{j}$ that is entered linearly is therefore equal to P. [1 P]. $\beta_{\mathrm{j}}$ (and analogously for a variable in $\mathbf{Z}$ ).
} 
concerned at each stage. $^{9}$

Consider first the impact of the welfare characteristics $(\mathbf{X})$. These are of little importance in the knowledge equation. Only one coefficient is significant at the 5 percent level, and this has the 'wrong' sign: a household with at least one stunted child is up to 15-20 percentage points less likely to know about the scheme, although there is some suggestion that households with more children (of all ages and any nutritional status) have somewhat better knowledge ( $\mathrm{t}=1.7)$. An LR test in fact fails to reject the model with the horizontal equity test variables alone at the 1 percent level. ${ }^{10}$ The results indicate that the change in knowledge with income shown earlier in Table 1 came about solely due to the association of income with the location variables. There is very little targeting arising through knowledge being associated with observed welfare characteristics.

The picture is quite different in the claims equation however, where the welfare characteristics are very important. In contrast to the situation for knowledge, the effect of income remains significant when other welfare controls are introduced, albeit diminished in size. ${ }^{11} \mathrm{~A}$ ten percent rise in income reduces the claim probability by up to one sixth, ceteris paribus. And not only are claims less likely from households with higher income, but also from those with more durable goods and those who own transport. Evaluating at the average probability of a claim conditional on knowledge, the marginal effect of one additional durable good (the index ranges from 0 to 1 ) is to reduce that probability by some 8 percentage points. Ownership of transport reduces the probability by up to 12 points. Households with more children, a female head, or unemployed members are all more likely to make claims, conditional on the other welfare characteristics - by up to nearly 25 percent points in the case of a female head. The long-term nutritional status of children is not associated with claims however and neither is ownership of a plot (almost universal in rural areas but also found in the majority of households in towns and cities) or livestock. ${ }^{12}$

Turning to awards, the negative effects on claims of the ownership of durables and of

\footnotetext{
${ }^{9}$ By construction we are interested in the self-selected sub-population. Even if interest extends to the full population we do not have a theory of individual and Mahalla behaviour that would point to exclusion restrictions to aid identification of correlations between unobservable factors in each equation.

${ }^{10}$ Twice the difference in log-likelihood from a model with the horizontal equity variables alone is 20.2, compared to a critical value of chi-squared at the $1 \%$ level with 9 d.f. of 21.7 .

11 The estimated coefficient on log income with no other variables in the claim equation is -0.74 and -0.54 if just horizontal equity controls are also included.

${ }^{12}$ We experimented with a large number of alternative specifications of agricultural assets variables but could not improve on the crude specification shown in the table. Variables that proved insignificant included the amount of land, imputed income from land (applying available estimates
} 
transport continue to a greater (transport) or lesser (durables) extent. Children, female headship, and unemployed members have not dissimilar effects to those in the claim and award equations. The award probability however rises with income - the coefficient is equal in size and opposite in sign to that for claims. However it is not significant at the 5 percent level (the much smaller sample size in the awards equation when comparing t-statistics with those in the claims equation should be borne in mind). It is hard to take this result at face value, not least since it is inconsistent with the impact of several other welfare indicators in the award equation. The conclusion that the Mahalla committees are consciously directing money towards richer applicants seems premature, but it is notable that the partial correlation with income in the award equation always has the "wrong" sign whatever specification we adopted. Another variable with a changed effect is the stunting dummy, with a coefficient equal in size and opposite in sign to that in the knowledge equation: the award probability falls with improved nutritional status, although the estimate is only significant at the 10 percent level. It is highly unlikely that the Mahallas are actually conducting anthropometric measurement in claimant households. Rather, the result suggests that 'idiosyncratic' information used by the Mahallas when making awards is correlated with this welfare indicator.

What about the impact of the horizontal inequity test variables $(\mathbf{Z})$ ? The log-likelihood values at the bottom of Table 2 show that their exclusion is rejected at the 1 percent level in all three equations. Benefit receipt is more common in Karakalpakstan due to better knowledge and a greater propensity to claim rather than to the decisions of the Mahallas over awards. The probability of a (knowledgeable) household of given welfare characteristics in Karakalpakstan making a claim is up to 17 percent points higher than that of a similar household in Tashkent or Fergana.

(Unconditional on any characteristic, the probability in Karakalpakstan is about 0.5 , compared to 0.3 in Fergana and a 0.2 in Tashkent.) Benefit is more widespread in rural areas because of notably better knowledge (although the estimated coefficient is not that well-determined), while the lower probability of receipt in towns comes about at the opposite end of the process: awards.

The findings concerning ethnicity are revealing. Central Asian households are much more knowledgeable of the scheme - by up to 20 percentage points - with the coefficient concerned being the best determined of any variable in the knowledge equation. This must reflect the nature of the Mahalla as a Central Asian institution. But households from this majority ethnic group are no more likely ceteris paribus to claim benefit, conditional on knowledge. There is some suggestion however that they are more likely to get benefit if they do make a claim, although the coefficient in the awards equation is not well determined. This latter finding may be evidence of discrimination in

at the level of the raion (district) of the potential output per hectare), and fruit tree and vine ownership. 
their favour by the Mahallas. (On the other, these households may differ systematically in welfare characteristics unmeasured in our survey but observable by the Mahallas.)

Table 3 summarises the results with predicted probabilities of knowledge, claim and award for two hypothetical households, one with 'low welfare' characteristics and one with 'high welfare' characteristics. (The two represent households at about the 10th and 90th percentiles for each characteristic in the full sample.) The predicted knowledge probability is actually higher for the high welfare household. This is a result driven entirely by the coefficient on the stunting dummy in Table 2. This aside, the predicted probabilities are essentially the same for the two types of household, reflecting the lack of impact of the other welfare variables. However, the claim probability differs enormously between high and low welfare households. The high welfare household is most unlikely to apply for benefit: there is a lot of self-targeting. And the predicted probability for the low welfare household is as high as 0.75 (although this of course means that the probability of not making a claim for this type of household is as much as a quarter). The award probabilities, conditional on claim and knowledge, also differ very substantially between the two types of household (although not as much in relative terms as for the claim probability). The low welfare household has a probability of benefit exceeding 0.9 . The concern here is that the high welfare household has a not insignificant probability of receiving an award: almost 0.25 . But overall the results must be seen as encouraging for the ability of households to self-target and of the local Mahalla committees to distinguish low from high welfare households.

\section{Conclusions}

Disaggregating the process of receipt of social assistance into knowledge, claim and award provides a lot more insight into targeting than merely looking at who receives benefit and who does not. The collection and use of information on each of these stages should be a priority in future research on the targeting of social assistance. We have demonstrated the advantages of disaggregation using a simple empirical framework that is readily applicable elsewhere. We have also shed light on the workings of a new social assistance scheme in a transition economy, Uzbekistan.

The Uzbek scheme embodies no formal necessary or sufficient conditions for benefit and provides an example of a very decentralised and flexible system of targeting. We have noted the achievements of the scheme at the end of Section 4 and these are a positive demonstration of the potential for flexible community-based schemes of social assistance. However, some less satisfactory results also emerge, which are a reminder of the drawbacks of informality and flexibility. The amounts of benefit paid to recipients are completely unrelated to observed measures of household well-being. And conditional on indicators of household welfare, households in certain 
parts of the country and those of Central Asian ethnicity are more likely to benefit.

A part of both the scheme's success and failure in targeting stems from the nature of the Mahalla as an institution in Uzbek society. This will have helped the social assistance scheme to be accepted locally as a poverty alleviation programme, promoting recognition of the 'rules of the game' (to the extent that they exist) and hence encouraging self-targeting. But it may have hindered knowledge of the scheme among Slav households and have discouraged some worthy potential claims. Community organisations with some of the same features are common in other parts of the world too, providing one potential route for delivering benefit to the needy. 


\section{$\underline{\text { References }}$}

Alderman, H (2002), "Do local officials know something we don't? Decentralization of targeted transfers in Albania", Journal of Public Economics, 83(3): 375-404.

Atkinson A B, (1995), “On Targeting Social Security: Theory and Western Experience with Family Benefits", in van de Walle D and Nead K (eds.), Public Spending and the Poor, John Hopkins University Press, Baltimore.

Atkinson A B and Micklewright J (1992), Economic Transformation in Eastern Europe and the Distribution of Income, Cambridge University Press.

Besley, T, and Kanbur, R, (1993), "The Principles of Targeting”, in Lipton, M and van der Gaag, J, (eds.), Including the Poor, The World Bank, Washington DC

Blundell, R, Fry, V, and Walker I (1988), "Modelling the Take-Up of Means-Tested Benefits: The Case of Housing Benefits in the UK", Economic Journal, 98:58-74.

Coudouel, A (1998), "Living Standards in Transition: The Case of Uzbekistan”, PhD Thesis, European University Institute, Florence.

Coudouel, A, Marnie, S, Micklewright, J (1998), 'Targeting Social Assistance in a Transition Economy: The Mahallas in Uzbekistan', Innocenti Occasional paper 63, UNICEF International Child Development Centre, Florence.

Coudouel, A, Marnie, S, Micklewright, J, and Shcherbakova G (1997), "Regional Differences in Living Standards in Uzbekistan" in J Falkingham, J Klugman, S Marnie and J Micklewright (eds.), Household Welfare in Central Asia, Macmillan, Basingstoke.

Duclos, J-Y (1995), "Modelling the Take-Up of State Support", Journal of Public Economics, 58: 391-415.

Galasso E and Ravallion M (2003), "Decentralised Targeting of an Anti-Poverty Program”, Journal of Public Economics, forthcoming.

Grosh, M (1994), Administering Targeted Social Programs in Latin America: From Platitudes to Practice, Regional and Sectoral Studies, The World Bank, Washington DC.

Micklewright J and Ismail S, (2002), "What Can Child Anthropometry Reveal About Living Standards and Public Policy? An Illustration from Central Asia", Review of Income and Wealth, March.

Pudney S (2001), "The Impact of Measurement Error in Probit Models of Benefit Take-Up", Department of Economics, University of Leicester

Pudney S (2003) "Measurement Error in a Structural Model of Welfare Participation: A Comment on a Study by Duclos", Department of Economics, University of Leicester

Weisbrod B A, (1970), "Collective Action and the Distribution of Income: A Conceptual Approach", in Haveman R H and Margolis J (eds.), Public Expenditure and Policy Analysis, Markham, Chicago.

World Bank (2000), Making Transition Work for Everyone. Poverty and Inequality in Europe and Central Asia, The World Bank, Washington DC. 
Table 1: Receipt, knowledge, claim and award by quintile groups of income

\begin{tabular}{|c|c|c|c|c|c|c|}
\hline $\begin{array}{l}\text { Income } \\
\text { quintile } \\
\text { group } \\
\text { (income net } \\
\text { of benefit) }\end{array}$ & $\begin{array}{c}1 . \\
\text { Benefit } \\
\text { received } \\
(\%)\end{array}$ & $\begin{array}{c}2 . \\
\text { Know } \\
\text { of the } \\
\text { scheme } \\
(\%)\end{array}$ & $\begin{array}{c}3 . \\
\text { Claimed } \\
\text { (among } \\
\text { those with } \\
\text { knowledge) } \\
(\%)\end{array}$ & $\begin{array}{c}4 . \\
\text { Awarded } \\
\text { (among } \\
\text { those who } \\
\text { claimed) } \\
(\%)\end{array}$ & $\begin{array}{c}5 . \\
\text { Average } \\
\text { benefit } \\
\text { among } \\
\text { recipients } \\
\text { (Uzbek sum) }\end{array}$ & $\begin{array}{c}6 . \\
\text { Share of } \\
\text { total benefit } \\
\text { expenditure } \\
(\%)\end{array}$ \\
\hline 1 (poorest) & 27.1 & 85.4 & 49.6 & 63.9 & 331 & 30.1 \\
\hline 2 & 27.4 & 86.9 & 43.5 & 72.5 & 377 & 31.4 \\
\hline 3 & 11.7 & 77.6 & 21.9 & 68.8 & 320 & 13.1 \\
\hline 4 & 14.4 & 75.5 & 25.0 & 76.2 & 317 & 14.0 \\
\hline 5 (richest) & 10.0 & 72.6 & 21.3 & 67.1 & 359 & 11.2 \\
\hline All hshlds. & 17.9 & 80.0 & 31.0 & 72.1 & 340 & 100.0 \\
\hline
\end{tabular}

Note. Sample size is 1,581 households. Households no longer receiving benefit are included among recipients in columns 3 and 3a. Income is that received in cash in the previous month (excluding income due but not received), excludes benefit from the Mahallas and is equivalised using the Uzbek Ministry of Labour equivalence scale, which embodies an elasticity of needs with respect to family size of about 0.7 . The 'sum' in column 4 refers to the name of the Uzbek currency. 


\begin{tabular}{|c|c|c|c|c|c|c|}
\hline & \multicolumn{2}{|c|}{$\mathrm{p}$ (knowledge) } & \multicolumn{2}{|c|}{ p(claim | knowledge $)$} & \multicolumn{2}{|c|}{$\begin{array}{l}\mathrm{p} \text { (award } \mid \text { claim } \\
\text { and knowledge) }\end{array}$} \\
\hline & coeff. & $|\mathrm{t}|$ & coeff. & $|t|$ & coeff. & $|\mathrm{t}|$ \\
\hline \multicolumn{7}{|l|}{ Welfare variables $(X)$} \\
\hline Income $(\log )$ & 0.07 & 0.7 & -0.32 & 3.1 & 0.34 & 1.8 \\
\hline Durable good index & -0.33 & 1.2 & -1.77 & 6.3 & -0.88 & 1.6 \\
\hline Owns transport & 0.25 & 1.4 & -0.51 & 3.1 & -1.03 & 3.4 \\
\hline Owns plot of land & 0.01 & 0.1 & 0.09 & 0.5 & 0.56 & 1.6 \\
\hline Owns livestock & 0.40 & 1.9 & -0.20 & 1.2 & -0.66 & 2.0 \\
\hline Children (number) & 0.09 & 1.7 & 0.20 & 4.8 & 0.23 & 2.8 \\
\hline Stunted child (0-6) present & -0.69 & 2.7 & 0.05 & 0.2 & 0.65 & 1.7 \\
\hline Female head & 0.37 & 1.7 & 0.94 & 3.8 & 0.67 & 1.3 \\
\hline Unemployed persons present & -0.15 & 0.9 & 0.46 & 2.9 & 0.62 & 2.1 \\
\hline \multicolumn{7}{|l|}{ Horizontal equity variables $(Z)$} \\
\hline Fergana & 0.09 & 0.4 & 0.03 & 0.1 & 0.22 & 0.4 \\
\hline Karakalpakstan & 0.41 & 1.5 & 0.66 & 2.5 & -0.34 & 0.6 \\
\hline Town & 0.13 & 0.5 & 0.25 & 1.0 & -1.48 & 3.2 \\
\hline Rural area & 0.60 & 2.2 & 0.20 & 0.8 & 0.13 & 0.3 \\
\hline Central Asian ethnicity & 0.82 & 4.5 & -0.16 & 0.7 & 0.74 & 1.7 \\
\hline Constant & 0.34 & 1.1 & -0.25 & 0.7 & -0.34 & 0.5 \\
\hline Log-L & \multicolumn{2}{|c|}{-681.2} & \multicolumn{2}{|l|}{-708.5} & \multicolumn{2}{|l|}{-213.1} \\
\hline Log-L with welfare variables only & \multicolumn{2}{|c|}{-701.4} & \multicolumn{2}{|l|}{-721.7} & \multicolumn{2}{|l|}{-235.1} \\
\hline Log-L with equity variables only & \multicolumn{2}{|c|}{-690.6} & \multicolumn{2}{|l|}{-780.0} & \multicolumn{2}{|l|}{-232.3} \\
\hline Log-L with constant only & \multicolumn{2}{|c|}{-753.4} & \multicolumn{2}{|l|}{-830.2} & \multicolumn{2}{|l|}{-250.3} \\
\hline Sample size & \multicolumn{2}{|c|}{1,581} & \multicolumn{2}{|l|}{1,291} & \multicolumn{2}{|l|}{405} \\
\hline
\end{tabular}

Note: The dependent variable in the claim equation takes the value 1 if a claim has ever been made. The award equation is estimated for the sub-sample of households who have made a claim, excluding those waiting for a decision on the claim; the dependent variable takes the value 1 if benefit was awarded irrespective of whether it is still in receipt. The durable good index is defined as follows: for each of 5 durable goods (fridge, colour TV, washing machine, tape recorder, sewing machine) a household scored ' 1 ' if the good is present; the total is then summed and divided by 5 (the index therefore ranges from 0 to 1 ). Income is defined as in Table 1 . All other variables are 0/1 dummies, except the number of children. 
Table 3: Predicted probabilities: knowledge, claim and award

Low welfare household High welfare household

\begin{tabular}{lll}
\hline $\mathrm{p}$ (knowledge) & 0.719 & 0.867 \\
$\mathrm{p}$ (claim | knowledge) & 0.743 & 0.039 \\
$\mathrm{p}$ (award | claim and knowledge) & 0.917 & 0.237 \\
\hline \hline
\end{tabular}

Note: The low welfare household has income at the bottom decile, no durable goods, no transport, no livestock (or plot), four children (of which one or more aged 0-6 and stunted) and at least one unemployed member. The high welfare household has income at the top decile, has 5 durable goods, a means of transport, livestock (and a plot), and no children or unemployed member. Horizontal equity characteristics are fixed at their means for both types of household. 